\title{
Application of the VUV and the soft x-ray systems on JET for the study of intrinsic impurity behavior in neon seeded hybrid discharges
}

N. Krawczyk, A. Czarnecka, I. Ivanova-Stanik, R. Zagórski, C. Challis, D. Frigione, C. Giroud, J. Graves, M. J. Mantsinen, S. Silburn, and JET Contributors

Citation: Review of Scientific Instruments 89, 10D131 (2018); doi: 10.1063/1.5038930

View online: https://doi.org/10.1063/1.5038930

View Table of Contents: http://aip.scitation.org/toc/rsi/89/10

Published by the American Institute of Physics

\section{Articles you may be interested in}

Plasma rotation measurement using UV and visible spectroscopy on Aditya-U tokamak

Review of Scientific Instruments 89, 10D132 (2018); 10.1063/1.5039333

Development of a $\mathrm{Z}_{\text {eff }}$ diagnostic using visible and near-infrared bremsstrahlung light for the C-2W fieldreversed configuration plasma

Review of Scientific Instruments 89, 10D130 (2018); 10.1063/1.5037588

Characterization and calibration of the Thomson scattering diagnostic suite for the C-2W field-reversed configuration experiment

Review of Scientific Instruments 89, 10C120 (2018); 10.1063/1.5037101

Simultaneous measurement of $\mathrm{C} \mathrm{VI,} \mathrm{Ne} \mathrm{X,} \mathrm{and} \mathrm{Li} \mathrm{III} \mathrm{charge} \mathrm{exchange} \mathrm{lines} \mathrm{on} \mathrm{EAST}$

Review of Scientific Instruments 89, 10D119 (2018); 10.1063/1.5036835

Motional Stark effect imaging first results on the DIII-D tokamak

Review of Scientific Instruments 89, 10D124 (2018); 10.1063/1.5038969

Application of portable near-infrared spectrometer to Heliotron $\mathrm{J}$ plasma diagnostics

Review of Scientific Instruments 89, 10D129 (2018); 10.1063/1.5039320

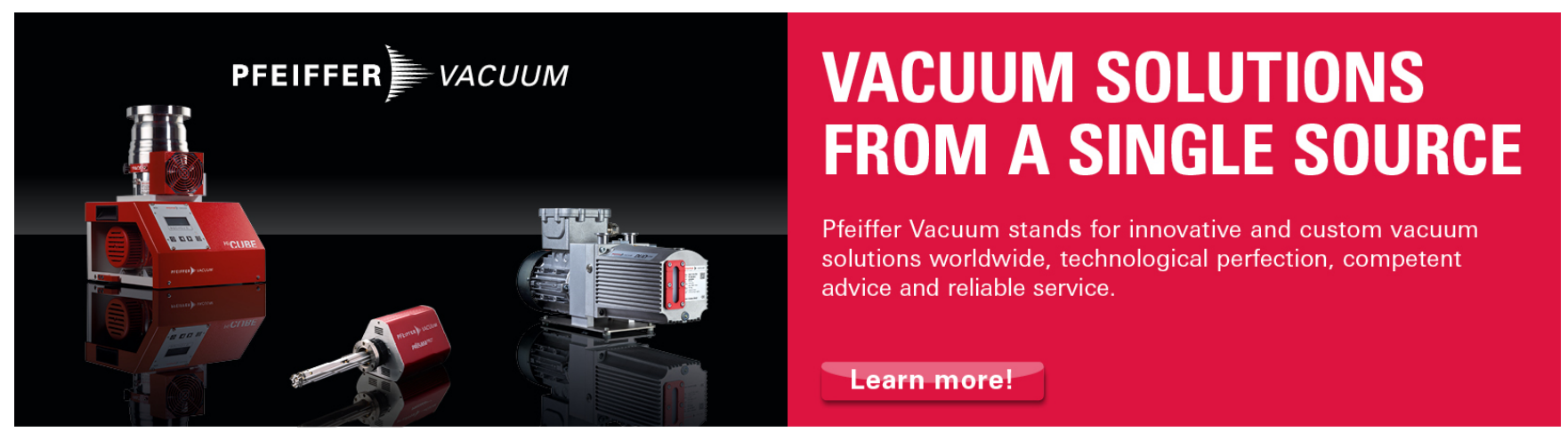




\title{
Application of the VUV and the soft x-ray systems on JET for the study of intrinsic impurity behavior in neon seeded hybrid discharges
}

\author{
N. Krawczyk, ${ }^{1, a)}$ A. Czarnecka, ${ }^{1}$ I. Ivanova-Stanik, ${ }^{1}$ R. Zagórski, ${ }^{1}$ C. Challis, ${ }^{2}$ D. Frigione, ${ }^{3}$ \\ C. Giroud, ${ }^{2}$ J. Graves, ${ }^{4}$ M. J. Mantsinen, ${ }^{5,6}$ S. Silburn, ${ }^{2}$ and JET Contributors $\left.{ }^{b}\right)$ \\ ${ }^{1}$ Institute of Plasma Physics and Laser Microfusion, Hery 23, Warsaw 01-497, Poland \\ ${ }^{2}$ CCFE, Culham Science Centre, Abingdon, Oxon OX14 3DB, United Kingdom \\ ${ }^{3}$ Associazione EURO-ENEA, C.R.E. Frascati, Frascati, Italy \\ ${ }^{4}$ Centre de Recherches en Physique des Plasmas, EPFL, Lausanne, Switzerland \\ ${ }^{5}$ ICREA, Barcelona, Spain \\ ${ }^{6}$ Barcelona Supercomputing Center, Barcelona, Spain
}

(Presented 17 April 2018; received 7 May 2018; accepted 10 July 2018; published online 24 October 2018)

\begin{abstract}
This paper reports on impurity behavior in a set of hybrid discharges with $\mathrm{Ne}$ seeding-one of the techniques considered to reduce the power load on reactor walls. A series of experiments carried out with light gas injection on JET with the ITER-Like-Wall (ILW) suggests increased tungsten release and impurity accumulation [C. Challis et al., Europhysics Conference Abstracts 41F, 2.153 (2017)]. The presented method relies mainly on the measurements collected by vacuum-ultra-violet and soft X-ray (SXR) diagnostics including the "SOXMOS" spectrometer and the SXR camera system. Both diagnostics have some limitations. Consequently, only a combination of measurements from these systems is able to provide comprehensive information about high-Z [e.g., tungsten (W)] and mid-Z [nickel (Ni), iron ( $\mathrm{Fe})$, copper $(\mathrm{Cu})$, and molybdenum (Mo)] impurities for their further quantitative diagnosis. Moreover, thanks to the large number of the SXR lines of sight, determination of a 2D radiation profile was also possible. Additionally, the experimental results were compared with numerical modeling based on integrated simulations with COREDIV. Detailed analysis confirmed that during seeding experiments, higher tungsten release is observed, which was also found in the past. Additionally, it was noticed that besides $\mathrm{W}$, the contribution of molybdenum to SXR radiation was greater, which can be explained by the place of its origin. https://doi.org/10.1063/1.5038930
\end{abstract}

\section{INTRODUCTION}

One of the critical issues in the context of future fusion reactors is divertor heat load limits. In order to reduce excessive heat fluxes to the targets plates, light impurity seeding [using, e.g., neon $(\mathrm{Ne})$, nitrogen $(\mathrm{N})$, argon (Ar), or a mixture of them] is considered. This approach is of paramount importance, especially with a view to a fully metallic device such as ASDEX-Upgrade (W wall and divertor) or JET with the ITER-Like-Wall (ILW with Be limiter and W divertor), or the planned ITER. This is a consequence of the fact that in the case of $\mathrm{W}$ and beryllium (Be) plasma facing components (PFCs), the radiation losses that occur naturally are estimated at a low level $\sim 25 \%-30 \%$ of the heating power, when, for instance, for carbon, elements are at least 50\%. ${ }^{2}$ Moreover, for different types of PFCs, different radiation patterns during $\mathrm{Ne}$ seeding are observed. For carbon (C) divertor, radiation is mainly located in the Scrape-Off Layer (SOL) and around the $\mathrm{X}$-point, while for $\mathrm{W}$ divertor, the dominant radiation was found in the plasma core. Until now, the most satisfactory results in terms of the reducing the heat load to the divertor

\footnotetext{
Note: Paper published as part of the Proceedings of the 22nd Topical Conference on High-Temperature Plasma Diagnostics, San Diego, California, April 2018.

a) Author to whom correspondence should be addressed: natalia.krawczyk@ifpilm.pl

b) See the authors list of X. Litaudon et al., Nucl. Fusion 57, 102001 (2017).
}

plates and good plasma confinement in tokamaks with metallic walls have been achieved during nitrogen injection. ${ }^{3,4}$ However, in considering which extrinsic impurity as a seeding gas should be applied, also its impact on the interaction with the PFCs is especially envisaged. In presented study, Ne seeding mainly due to its operational compatibility with the JET tritium handling facility has been chosen. ${ }^{1}$ Whereas the injections of light impurities are appropriate for maintaining the power load to the, e.g., divertor at an acceptable level, high-Z contamination in the plasma center was observed in parallel (depending on electron density and temperature profiles). ${ }^{1}$ Moreover, as it was observed in JET, mid-Z impurities such as $\mathrm{Ni}, \mathrm{Fe}, \mathrm{Cu}$, and $\mathrm{Mo}$ can contribute significantly to the total radiated power. ${ }^{5}$ In this paper, as opposed to results presented in previous publications concerning light impurities seeding, ${ }^{6-8}$ there is a complex overview of mid- and high- $\mathrm{Z}$ impurity concentrations as well as radiation by using data from multiple diagnostics. It is important due to the weaknesses of different diagnostics, which are described in Sec. II.

\section{SETUP OF DIAGNOSTICS FOR IMPURITY MEASUREMENTS AT JET}

A study of $\mathrm{W}$ behavior in JET plasmas is realised with a diagnostic set combining the soft X-ray (SXR) cameras and a vacuum-ultra-violet (VUV) Schwob-Fraenkel SOXMOS ${ }^{9}$ 
spectrometer, called KT7/3 diagnostic at JET. The first mentioned system consists of horizontal $(\mathrm{H})$ and vertical $(\mathrm{V}, \mathrm{T})$ cameras. ${ }^{10}$ In the case of the presented analysis, only the Vcamera, with the large number of lines of sight (LOS) (see Fig. 1), was used to determine $\mathrm{W}$ concentration profiles on the basis of a tomographic reconstruction of the registered signals. The maximum acquisition frequency of the vertical camera is $0.2 \mathrm{MHz}$. With this diagnostic, poloidal asymmetries that are caused by centrifugal forces can be obtained as well. ${ }^{11}$ Results provided by using SXR cameras are based on the assumption that the main radiator is $\mathrm{W}$, while the radiation from other metallic impurities is negligible. ${ }^{11}$ To predict the local SXR emissivity due to bremsstrahlung, it is assumed that only $\mathrm{Be}$, and $\mathrm{Ne}$ as the low-Z impurities, gives rise to bremsstrahlung. This is implemented using the effective charge $\mathrm{Z}_{\text {eff }}$ measurements from the visible bremsstrahlung measurement KS3:ZEFH. Moreover, SXR analysis is performed when Te $>1.5-2 \mathrm{keV}$, what constitutes another limitation in the analysis. Nevertheless, it needs to be emphasized that the main weakness of the presented method is assumption about $\mathrm{W}$ and its dominant role in the plasma radiation. It is not exactly clear what species in the plasma have contribution to the soft x-ray radiation, as well as in what quantities. Quantitative diagnosis of the W content by the use of SXR cameras is described in detail in Ref. 12. The SOXMOS spectrometer with the $600 \mathrm{~g} / \mathrm{mm}$ grating is set to record spectra in the wavelength range from 4 to $7 \mathrm{~nm}$. In this spectral region, $\mathrm{W}$-ions from $\mathrm{W}^{27+}$ to $\mathrm{W}^{35+}$ are emitted. This particular kind of quasicontinuum, which occurs when the electron temperature is in the range between 0.8 and $1.8 \mathrm{keV}$, is used for a quantitative determination of $\mathrm{W}$ concentration. Consequently, due to the limited radial range, where $\mathrm{T}_{\mathrm{e}}$ is sufficient for proper diagnostic operation, there is some lack of the provided $\mathrm{W}$ content. $^{12}$ In the case of $\mathrm{KT} 7 / 3$, there is also a restriction in the form of $\mathrm{Te}>5 \mathrm{keV}$-above this value, the system

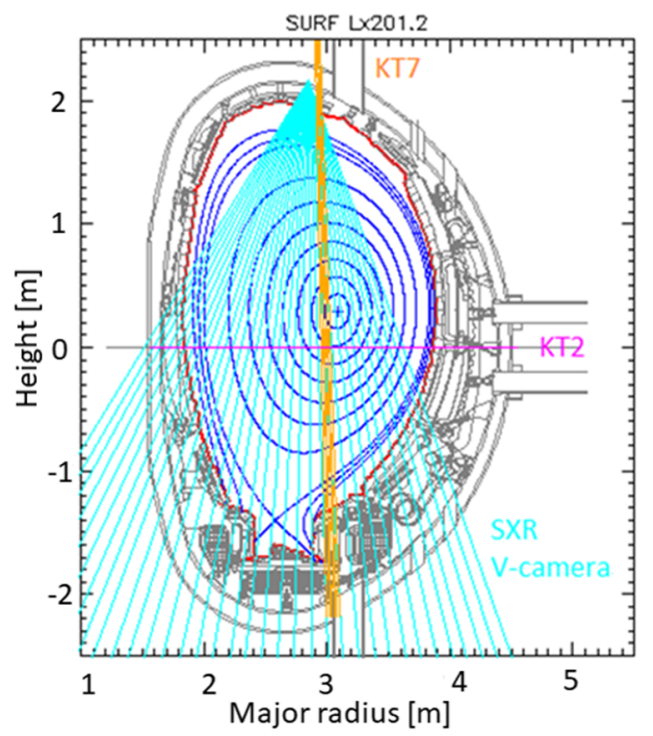

FIG. 1. Diagnostic setup for determining mid- and high- $Z$ impurities. The lines of sight of vertical SXR cameras (blue) as well as KT2 (pink) and KT7/3 (orange) VUV spectrometers with the magnetic equilibrium of JET pulse No: 90337 at $5.75 \mathrm{~s}$. cannot register data. Another important point is that in the case of plasma asymmetry, due to LOS of KT7/3 diagnostic, some part of $\mathrm{W}$ radiation can be lost. Therefore, taking into account both the limitations resulting from the assumptions used for the data analysis and physical parameters of diagnostics, only combining the results from the presented systems gives the possibility to comprehensive analysis of high- $Z$ impurities behavior. Then, in the next step, to verify the results from $\mathrm{W}$-diagnostics, it is also advisable to examine the level of, e.g., Ni and other mid-Z impurities, which shall also play a significant role in this kind of analysis. This proposed approach primarily should allow assessment of the correctness of the assumption about $\mathrm{Z}_{\mathrm{eff}}$ and possible contribution to the soft $\mathrm{x}$-ray radiation. For this purpose, the VUV survey spectrometer (known as KT2 $2^{12,13}$ diagnostic at JET), which is mainly intended for the quantitative diagnosis of mid-Z impurities, was used. In the wavelength range scanned by using the KT2, it is possible to observe different mid- $Z$ impurities like nickel (Ni), iron (Fe), molybdenum (Mo), or copper (Cu). This system equipped with $4500 \mathrm{~g} / \mathrm{m}$ holographic grating is able to observe the spectrum from 100 to $1100 \dot{\mathrm{A}}$, while its spectral resolution is around $5 \dot{\mathrm{A}}$. Despite the fact that the best possible time resolution of this diagnostic is $11 \mathrm{~ms}$, the microchannel plate coupled to a 2048 Photodiode Array (PDA) usually collects data from 20 to $50 \mathrm{~ms}$ time intervals. The relative calibration of this system at short wavelengths is described in Ref. 14. The method used for determining mid-Z impurity concentration and $\Delta Z_{\text {eff }}$ (in steady-state JET plasmas by the use of passive VUV emission) is based on the absolutely calibrated VUV transition intensity measurements, as well as Universal Transport Code (UTC) simulations. In order to reproduce the intensity of mid-Z lines, UTC uses a wide class of transport coefficients. For a specific set of the diffusion $(\mathrm{D}(\mathrm{r}))$ and convection velocity $(\mathrm{v}(\mathrm{r}))$, the simulated line intensity is matched to the line intensity measured in the experiment. Then it is possible to establish a linear fit using the dependence of the ratio between the obtained impurity densities and the line density on local electron temperature. Such an approximately linear fit allows us to calculate the local mid-Z impurity density in the mid-radius plasma region. The mentioned method is presented in detail by Czarnecka et al. in Ref. 15. For determination of high-Z and mid-Z impurity concentrations, electron temperature $\left(\mathrm{T}_{\mathrm{e}}\right)$ and electron density $\left(\mathrm{n}_{\mathrm{e}}\right)$ profiles from a high resolution Thomson scattering (HRTS) system are taken into account. The setup of the discussed diagnostics and their LOS is presented in Fig. 1.

\section{EXPERIMENTAL AND SIMULATION RESULTS}

This work investigates a set of hybrid discharges, where Ne was injected from GIM9 in the divertor private flux region, and its rate was changed from pulse to pulse. At the same time, other parameters such as the plasma current $\left(I_{p}\right)$, magnetic field $\left(\mathrm{B}_{\mathrm{T}}\right)$, and neutral beam injection (NBI) were kept the same at 1.4 MA, 1.9 T, and 16.3 MW, respectively. The series of the studied discharges consists of 5 pulses with increasing $\mathrm{Ne}$ seeding rate (\#90336, \#90337, \#90339, $\# 90279$, and \#90280), as well as reference one, without any injection of external impurity (\#90287). Moreover, in 
all of them, additional deuterium gas fueling was equal $\sim 1.5 \times 10^{22} \mathrm{e} / \mathrm{s}$, while a wide region of low magnetic shear with $\mathrm{q}_{0} \sim 1$ was created and $\beta_{\mathrm{n}}$ was limited to $\sim 2.2$. Due to the low magnetic field, radio frequency (RF) heating was not applied. For this reason, radiative collapse and plasma disruption caused by $\mathrm{W}$ accumulation were more likely. The first observation shows that after Ne injection into JET hybrid plasmas, the divertor surface temperature was significantly reduced, while radiated power $\left(\mathrm{P}_{\mathrm{rad}}\right)$ and effective charge $\mathrm{Z}_{\text {eff }}$ (from the visible bremsstrahlung measurement KS3:ZEFH) increased, which is presented in Fig. 2. As can been seen, increased $\mathrm{W}$ release from PFCs has been observed by using the SXR camera system in the core plasma $(\mathrm{r} / \mathrm{a}=0)$ as well as at the mid-radius $(\mathrm{r} / \mathrm{a}=0.45)$. This behavior is not present close to the plasma edge $(\mathrm{r} / \mathrm{a}=0.7)$ as shown by data obtained with the VUV spectrometer. The error bars correspond to an uncertainty of the measured electron densities and temperatures.

Additionally, experimental results were supported by simulations using the COREDIV code. ${ }^{16}$ This numerical modeling of plasma parameters solves the 1D radial transport equations of plasma and impurities in the core region and 2D multi-fluid transport in the SOL. In the case of presented analysis, simulations for the radial diffusion in SOL with $\mathrm{D}^{\mathrm{SOL}}$ rad $=0.5 \mathrm{~m}^{2} / \mathrm{s}$ were carried out. In the core plasma, a simply neo-classical model was assumed. The SOL region was approximated by a simple slab geometry (poloidal and radial direction) with classical transport in the poloidal direction and anomalous transport in radial direction using the following transport coefficients $\mathrm{Di}=\chi \mathrm{i}=0.5 \chi \mathrm{e}$. Similarly as in the core part of the model, it was assumed that for all ions, the anomalous transport is the same and they have the same temperature. What is also important, hybrid discharges selected for this paper were characterized by the magnetic configuration with the outer strike point close to the pump out valve (the so-called corner configuration). This configuration has some implications for the modeling of the $\mathrm{W}$ penetration into the plasma. The $\mathrm{W}$ atoms which enter the divertor plasma represent only a small fraction of the sputtered ones due to prompt re-deposition processes. Therefore, to reproduce lower radiation, the prompt re-deposition model was included in simulation. In these simulations, the $\mathrm{W}$ source is calculated from sputtering processes (calculated from Ref. 17) by main ions (D), impurity: seeded $(\mathrm{Ne}, \mathrm{Ni})$ and intrinsic $(\mathrm{Be})$ and self-sputtering. As is presented



FIG. 2. Radiated power $\left(\mathrm{P}_{\mathrm{rad}}\right)$ for the main chamber only and effective charge $\left(Z_{\text {eff }}\right)$ versus the Ne seeding rate.

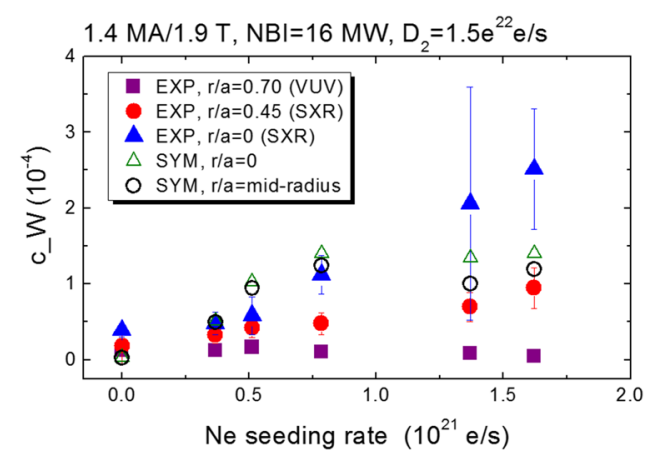

FIG. 3. Comparison of $\mathrm{W}$ concentration obtained by using the SXR system and VUV spectrometer with the modeling one based on simulation with the COREDIV code for different plasma radii (especially in the plasma core and at mid-radius).

in Fig. 3, experimental results concerning $\mathrm{W}$ are consistent with numerical modeling from COREDIV due to the fact that also simulations indicate a noticeable increase in $\mathrm{W}$ concentration for the plasma core and mid-radius region. The discussed trend is also visible in 2D deconvolutions of SXR signals, as shown in Fig. 4. The presented reconstructions were carried out for $\mathrm{t}=5.75 \mathrm{~s}$, while the SXR upper range was equal to $25.1 \mathrm{~kW} / \mathrm{m}^{3}$.

At the same time, the rotation velocity resulting from the poloidal in-out asymmetry (observed in the SXR) was compared with that measured by charge exchange recombination spectroscopy (CXRS). This comparison suggests that for higher Ne seeding rate, besides $\mathrm{W}$ also Mo is contributing to the SXR radiation. This dependence is also confirmed by measurements provided by using the VUV spectrometer. Figure 5 shows the increase in the Mo content with the $\mathrm{Ne}$ seeding rate. It is worth emphasizing that the Mo as an interlayer in the divertor tiles comes from the same region as $\mathrm{W}$,

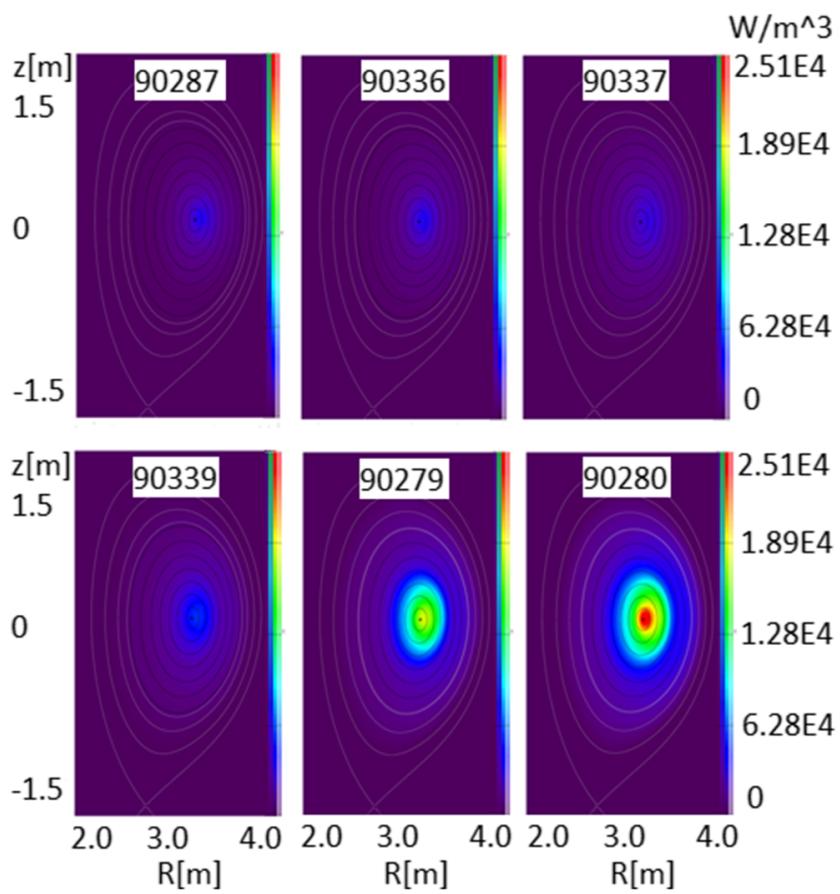

FIG. 4. 2D-profiles of SXR-radiation for set of discharges with Ne seeding obtained from the SXR camera system. 


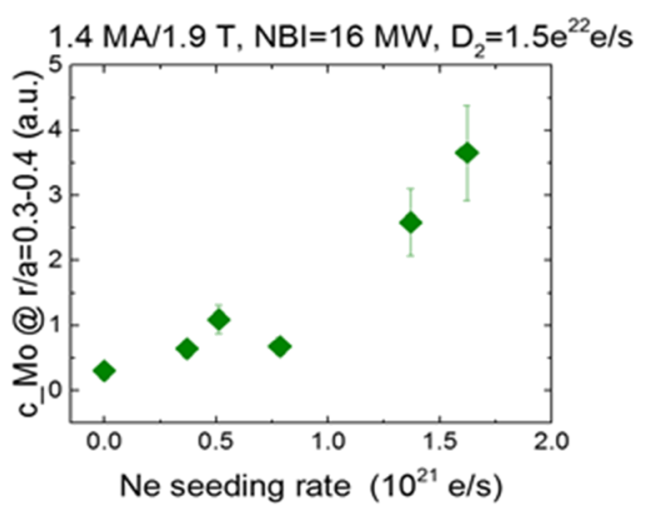

FIG. 5. Mo concentration obtained by using the VUV spectrometer for the plasma region $\mathrm{r} / \mathrm{a}=0.3-0.4$.

what can explain their similar behavior during the presented experiment. Therefore, on the basis of results concerning $\mathrm{W}$ and Mo, it was proved that these impurities can tend to accumulate in the plasma core during light impurity seeding what requires its further studying for their future control. A different trend is observed for mid-Z impurities such as $\mathrm{Ni}$, $\mathrm{Cu}$, and $\mathrm{Fe}$. In the case of $\mathrm{Ni}$ (determined on the basis of Ref. 15), its production comes from structures within the vacuum vessel or is caused by contamination of the plasma facing components. For this reason, the effect of $\mathrm{Ne}$ seeding on $\mathrm{Ni}$ production should be significantly different compared to $\mathrm{W}$ and Mo release. As Fig. 6 shows, a decrease in the Ni intensity line with the increase in the $\mathrm{Ne}$ seeding rate was observed for the plasma region $\mathrm{r} / \mathrm{a}=0.3-0.4$. This trend was confirmed by simulations which rely on an assumption that the Ni source is by gas puff in midplane $\left(\Gamma \mathrm{Ni}=1.5 \times 10^{19} 1 / \mathrm{s}\right)$, with recycling coefficient $\left(\mathrm{R}_{\mathrm{RECYC}}=0.25\right)$ and it remains unchanged for all discharges.

Additionally, total $\mathrm{Ni}$ radiation for two marginal discharges - characterized by the lowest (\#90336) and the highest (\#90280) amount of injected $\mathrm{Ne}$, has been modeled.

Figure 7 shows this parameter as a function of the plasma radius. As in the case of W (see Fig. 4), here it is possible to observe higher radiation for the case of higher seeding. It is due to the fact that for the pulse \#90280, we observed higher plasma density (ne) and lower electron temperature (Te) in comparison with \#90336. In turn, these two parameters have a significant impact on the cooling factor rate, which in addition to plasma

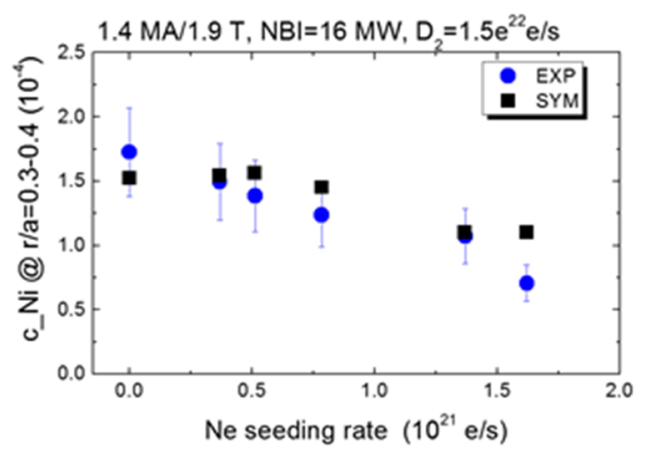

FIG. 6. Comparison of Ni concentration obtained by using the VUV spectrometer with the modeling one based on simulation with the COREDIV code for the plasma region $\mathrm{r} / \mathrm{a}=0.3-0.4$.

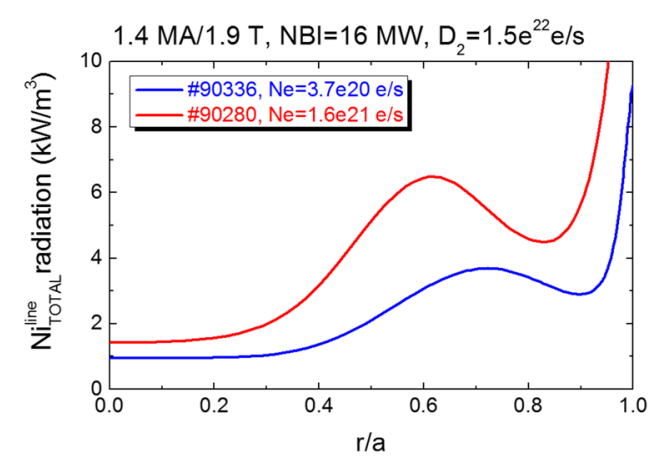

FIG. 7. Comparison of simulated Ni radiation for two discharges with different Ne seeding rates.

volume (V), Ne, and impurity density (nZ) is proportional to the calculated Ni radiation. However, it is worth noting that despite a similar trend for these two types of impurities (highand mid-Z), the total $\mathrm{Ni}$ radiation is an order of magnitude smaller than in the case of W (see Fig. 4). Other mid-Z impurities like $\mathrm{Fe}$ and $\mathrm{Cu}$ behaved in a comparable way such as $\mathrm{Ni}$ during the experiment. Nevertheless, the decreasing tendency is more noticeable for $\mathrm{Fe}$ concentration presented in Fig. 8. At the same time, the $\mathrm{Cu}$ content remains more stable with $\mathrm{Ne}$ seeding. It can be caused by its different origin-material from the NBI system. Moreover, it is worth emphasizing that in contrast to $\mathrm{Ni}, \mathrm{Fe}$ and $\mathrm{Cu}$ concentrations at a plasma radius $\mathrm{r} / \mathrm{a}=0.3-0.4$ were very small. It means that they had no

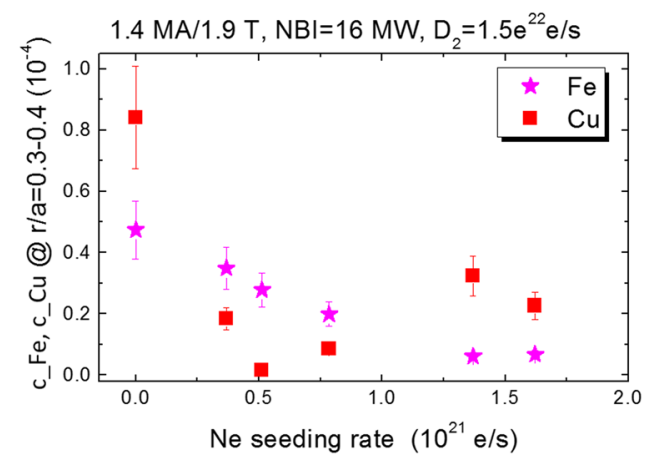

FIG. 8. Iron ( $\mathrm{Fe})$ and copper $(\mathrm{Cu})$ intensity versus neon $(\mathrm{Ne})$ seeding rate for the plasma radius $\mathrm{r} / \mathrm{a}=0.3-0.4$ on the basis of data from KT2.

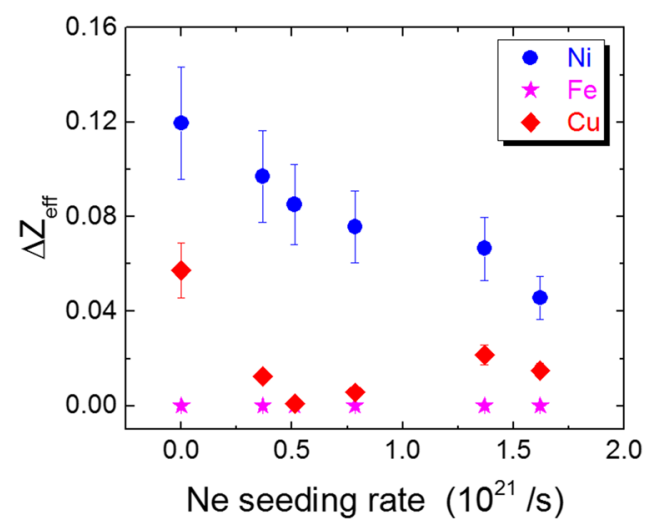

FIG. 9. Incremental $\mathrm{Z}_{\mathrm{eff}}$ delivered from $\mathrm{Ni}, \mathrm{Fe}$, and $\mathrm{Cu}$ using VUV diagnostic as a function of the Ne seeding rate. 
significant effect on the calculated effective charge. To confirm this assumption, incremental $\mathrm{Z}_{\text {eff }}$ (resulting as presented in this paper) mid-Z impurities were estimated. As can be seen from Fig. 9, incremental effective charge derived from $\mathrm{Ni}, \mathrm{Fe}$, and $\mathrm{Cu}$ is very low. It shows that the increase in Zeff is dominated by the increase in $\mathrm{Ne}$, while the mid- $\mathrm{Z}$ impurities like $\mathrm{Ni}, \mathrm{Fe}$, and $\mathrm{Cu}$ are negligible. Moreover, despite the fact that $\mathrm{W}$ is released more with Ne seeding, its contribution to $Z_{\text {eff, }}$ as a high-Z impurity, is also insignificant.

\section{CONCLUSIONS}

This paper presents a study of the core impurity content and their radiation for discharges in which $\mathrm{Ne}$ seeding was used to reduce the heat flux to divertor targets. The proposed method for the evaluation of composition and quantitative diagnosis of impurities confirmed that $\mathrm{Ne}$ seeding, injected from a divertor GIM, can lead to increased W and Mo release (as a part of divertor components) by the sputtering process. Such high-Z impurity behavior can have a detrimental effect on plasma performance. In the case of mid-Z impurities like $\mathrm{Ni}$ or $\mathrm{Fe}$, with the larger amount of injected gas, their concentration decreased. It can be explained by the fact that mentioned mid-Z impurities are located outside the divertor region, where $\mathrm{Ne}$ seeding was directly applied. For this reason, the process of their release was almost negligible in comparison with $\mathrm{W}$ and Mo. Additionally, it is worth to add that, e.g., in the case of $\mathrm{Ni}$, its higher release is usually correlated with RF heating, while during the presented experiment, only NBI heating was in use. What is also important, results obtained by analysis of the experimental data were consistent with those simulated with the COREDIV code.

\section{ACKNOWLEDGMENTS}

This work has been carried out within the framework of the EUROfusion Consortium and has received funding from the Euratom research and training programme 2014-2018 under Grant Agreement No. 633053. The views and opinions expressed herein do not necessarily reflect those of the
European Commission. This scientific work was partly supported by the Polish Ministry of Science and Higher Education within the framework of the scientific financial resources in the years 2014-2018 allocated for the realization of the international co-financed project.

${ }^{1}$ C. Challis et al., Europhysics Conference Abstracts 41F, 2.153 (2017), see https://www.bsc.es/research-and-development/publications/impact-neonseeding-fusion-performance-jet-ilw-hybrid-plasmas.

${ }^{2}$ G. Telesca et al., Nucl. Mater. Energy 12, 882-886 (2017).

${ }^{3}$ J. Schweinzer et al., Nucl. Fusion 51, 113003 (2011).

${ }^{4}$ C. Giroud et al., Nucl. Fusion 53, 113025 (2013).

${ }^{5}$ M. J. Mantsinen et al., EPJ Web of Conferences 157, 03032 (2017).

${ }^{6}$ G. Telesca, I. Ivanova-Stanik, R. Zagorski, S. Brezinsek, A. Czarnecka, P. Drewelow, C. Giroud, S. Marsen, M. Wischmeier, and JET EFDA Contributors, "Numerical simulations of JET discharges with the ITER-like wall for different nitrogen seeding scenarios," J. Nucl. Mater. 463, 577-581 (2015).

${ }^{7}$ G. Telesca, I. Ivanova-Stanik, R. Zagórski, S. Brezinsek, A. Czarnecka, P. Drewelow, C. Giroud, A. Huber, S. Wiesen, and M. Wischmeier, "Simulation of JET ITER-like wall pulses at high neon seeding rate," Nucl. Fusion 57, 126021 (2017).

${ }^{8}$ G. Telesca, I. Ivanova-Stanik, R. Zagórski, S. Brezinsek, A. Czarnecka, P. Drewelow, C. Giroud, A. Huber, S. Wiesen, and JET Contributors, "CoreSOL modelling of neon seeded JET discharges with the ITER-like wall," Contrib. Plasma Phys. 56, 748-753 (2016).

${ }^{9}$ J. L. Schwob, A. W. Wouters, S. Suckewer, and M. Finkenthal, Rev. Sci. Instrum. 58, 1601 (1987).

${ }^{10}$ J. Mlynar et al., "Soft x-ray tomographic reconstruction of JET ILW plasmas with tungsten impurity and different spectral response of detectors," in Proceedings of the 28th Symposium on Fusion Technology SOFT, San Sebastian, Spain, 29 September-3 October 2014.

${ }^{11}$ T. Putterich et al., Plasma Phys. Controlled Fusion 55, 124036 (2013).

${ }^{12} \mathrm{~T}$. Putterich et al., in Proceedings of 24th IAEA Fusion Energy Conference, San Diego, CA, 8-13 October 2012 (IAEA, Vienna, 2012), Vol. IAEA-CN-197, EX-P3.15, http://www-naweb.iaea.org/napc/ physics/FEC/FEC2012/papers/193_EXP315.pdf.

${ }^{13} \mathrm{~K}$. D. Lawson et al., "An absolute sensitivity calibration of the JET VUV SPRED spectrometer," J. Instrum. 4, P04013 (2009).

${ }^{14} \mathrm{~A}$. Czarnecka et al., "Analysis of metallic impurity content by means of VUV and SXR diagnostics in hybrid discharges with hot-spots on the JETILW poloidal limiter," Plasma Phys. Controlled Fusion (to be published).

${ }^{15}$ A. Czarnecka, K.-D. Zastrow, J. Rzadkiewicz, I. H. Coffey, K. D. Lawson, and M. G. O'Mullane, Plasma Phys. Controlled Fusion 53, 035009 (2011).

${ }^{16} \mathrm{R}$. Zagorski et al., "Modelling with COREDIV code of JET ILW configuration," Contrib. Plasma Phys. 50, 306 (2010).

${ }^{17}$ R. Y. Yamamura et al., Report IPPJ-AM-26, Institute of Plasma Physics, Nagoya University, 1983. 